\title{
Optimization of Car Rim Using OptiStruct
}

\author{
Mr. P. H. Yadav ${ }^{1}$, Dr. P. G. Ramdasi ${ }^{2}$ \\ ${ }^{\text {I }}$ Post Graduation student, Rajarambapu Institute of Technology, Sakharale, India) \\ ${ }^{2}$ (Professor, Walchand College of Engineering, Sangli, India)
}

\begin{abstract}
Automobile industries requière manufacturing véhicules at optimum coste and with greater safety. For this purpose every component of vehicle is analysed for critical conditions. In this work car rim is considered for optimization by using finite element method. The optimization is carried to minimize the weight of rim without exceeding allowable strain. The intention is to create the geometry utilizing parameters for all the variables, deciding which variables to use as design, state and objective variables to obtain an accurately converged solution. FEM software OptiStruct is used for optimization of rim. If the stress \& strain values are within the permissible range, then certain dimensions are modified to reduce the amount of material needed. The procedure is repeated until design changes satisfy all the criteria. For experimental verification similar type of object is used and stresses in it are calculated for set load with suitable instrumentation. Then same is calculated in OptiStruct software and Experimental results are compared with FEM results.
\end{abstract}

Keywords: Impact factor, Strain gauge, Vonmises stress, Optistruct, Strain indicator.

\section{Introduction}

As part of technological improvement, comfort and safety have become essential demands of human beings. This comes not only from market-oriented competition but also from legislation that may seek some certain standards. Cars, important feature of technological development, are widely used in daily life. It seems that mankind no longer lives without them. Therefore, these wonderful machines should be safe and economical so that people could use them safely and more people could purchase them. Since rims, on which cars move, are the most vital elements in a vehicle, they must be designed carefully. The rims manufactured by various methods are made of either steel or cast aluminium alloys. In particular, rims made of aluminium casting alloys are more preferred because of the weight and the cost effectiveness [1].

Each part of a vehicle is certainly important for various reasons, such as safety and cost effectiveness. Therefore, some researchers have studied railroad car wheel by using rectangular elements, some have investigated rotating wheel. However significant research has also been on worked on optimum designs of different rotating discs.

The objective is to investigate the dynamic buckling characteristics of super cavitating bodies, modeled as elastic shells. The buckling loads are considered to vary periodically in time and are defined in terms of the speed of the vehicle, and period and amplitude of the oscillations. The influence of these parameters on the shell's dynamic stability is assessed through a finite element (FE) model, formulated to predict mass and stiffness properties of the considered class of shells [2]. The configurations are applied and used as means for enhancing the shells' stability. The stiffening rings have been already proposed to reduce vibrations in super cavitating vehicles resulting from their periodic impacts with the cavity water/interface (tail-slaps). The results presented indicate that the stiffening rings may be optimized in order to simultaneously achieve vibration reduction and enhanced buckling stability $[2,3]$.

The vibration behavior of shell structure studied by many methods of analysis is has considerable engineering importance. For example, closed form solutions for classical shell geometries under various boundary conditions have been obtained for the dynamic analysis. To study the vibration of shell structures, various structural approaches based on the finite discreation method, i. e. finite difference, finite strip, boundary element, and finite element method, have been used. In FEA variety of new finite elements have been proposed based on different structural theories in order to achieve a more accurate prediction of the structural response [4].

To put together the shell elements have a lot of practical significance. The shell element has been a great use for some of the analysis which is very typical in definition. The use of these elements enables the analysis to investigate the behavior of the structure under usual loading conditions in fluid mechanics. Hence it is taken up as analysis work.

\section{Objective}

The primary objective of this study is to carry out the weight optimization of a car rim by using finite element analysis. The analysis of rim shown in fig. 1 is carried out initially with the help of OptiStruct software. 
In the solution of the problem, FEM, whose meshes include quadrilateral linear elements with eight nodes is used. For experimental verification the actual testing of rim is not possible. For this purpose simple thin cylindrical component is studied experimentally. Same component is again tested in OptiStruct software. Since results of simple component in OptiStruct are matches with experimental results there for the results of rim obtained in ansys are also true. The load applied to the rim was assumed to be steady, that is, time independent. The load on rim is calculated with considering laden weight of car as $1000 \mathrm{~kg}$. By calculation it is found that maximum load acting on rear wheel of car rim and its value is $270 \mathrm{~kg}$ at each wheel. Again since the car is a light weight therefore consider by considering impact factor $2 \mathrm{G}$ when wheel of car rim faces the bump during running condition.

Therefore total Force on wheel Rim $=271 \times 2 \times 9.81=5317 \mathrm{~N}$.

Approximately it is considered as $5350 \mathrm{~N}$ load for analysis.

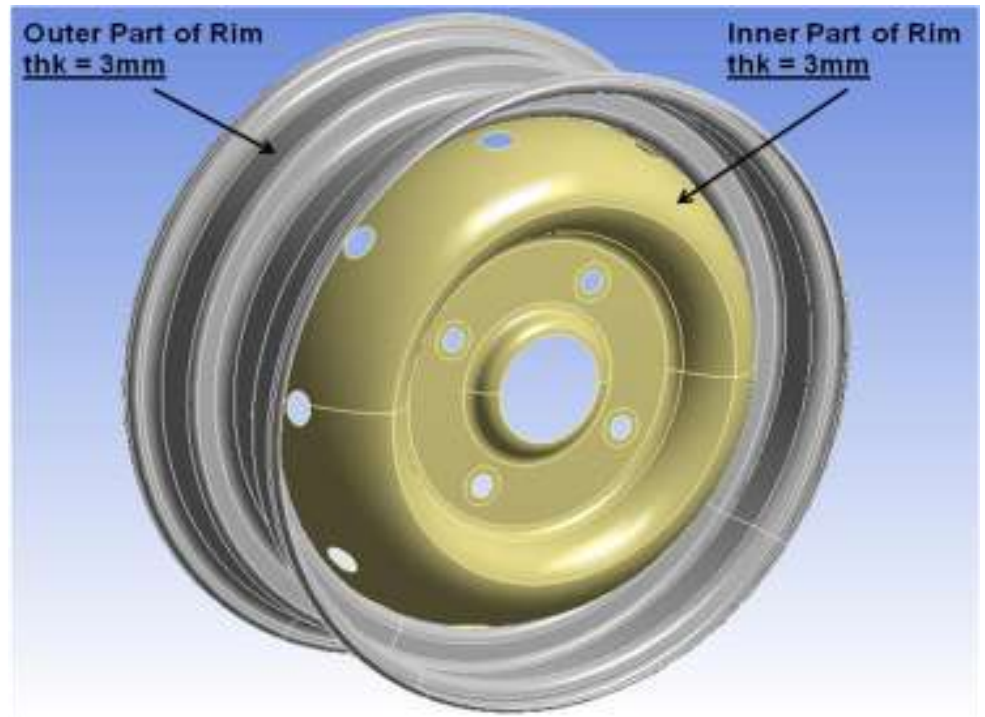

Fig. 1. 3-D model of car rim.

The mechanical properties of the rim material G-Al Si7 Mg in the norm of DIN (see the norms of A356), an aluminium casting alloy and (Si: 7.0; Mg: 0.5), were determined in a universal Instron machine by testing the specimens cut out from the rim. These properties are presented inTable 1

Table 1. Properties of the rim material

\begin{tabular}{|l|l|}
\hline Material Properties & Value \\
\hline Elasticity modulus, $\mathrm{E}$ & $70 \mathrm{Gpa}$ \\
\hline Poisson's ratio, $\eta$ & 0.34 \\
\hline Yield stress, $\sigma_{\mathrm{y}}$ & $70 \mathrm{Gpa}$ \\
\hline Hardening parameter, $\mathrm{K}$ & $513 \mathrm{mpa}$ \\
\hline Strain hardening exponent, $\mathrm{n}$ & 0.545 \\
\hline Density, $\rho$ & $2700 \mathrm{~kg} / \mathrm{m}^{3}$ \\
\hline
\end{tabular}

\section{FEA Analysis Of Car Rim}

The commercial finite element package Altair OptiStruct, module of Hyperworks was used for the FE modeling, meshing and analysis of rim. The geometric model for the rim was created based on the drawing. Element type P- shell element was selected for analysis, as it has a quadratic displacement behavior \& is well suited to model irregular mesh [5,6]. Then element material properties were assigned. After assigning the material properties the model was meshed by using mesh tool of Hyper works. The next step was the definition of the boundary conditions. All degrees of freedom are constrained at the bolting region of the rim model. The next step was the definition of the loads. The force of $5350 \mathrm{~N}$ was applied on the bottom face over the angle of $80^{\circ}$ as shown in fig. 2 


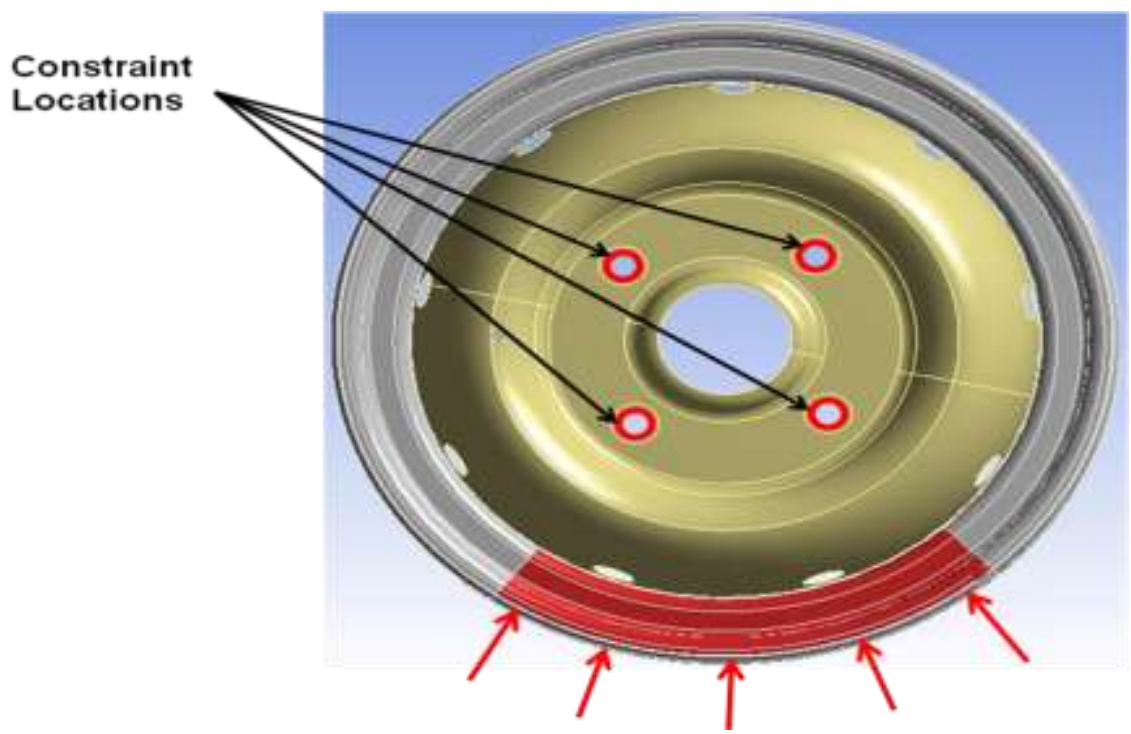

Fig. 2. Loading and boundry condition.

The static analysis of load cell was carried out. The finite element model was solved under given conditions. After obtaining the solution the results of analysis can be reviewed using post processing to determine maximum induced strain and stress and its location [7].

Different cases considered for the analysis of rim are as follows.

\subsection{Stress analysis of existing car rim:-}

After loading the displacement plot of rim is as shown in fig. 3
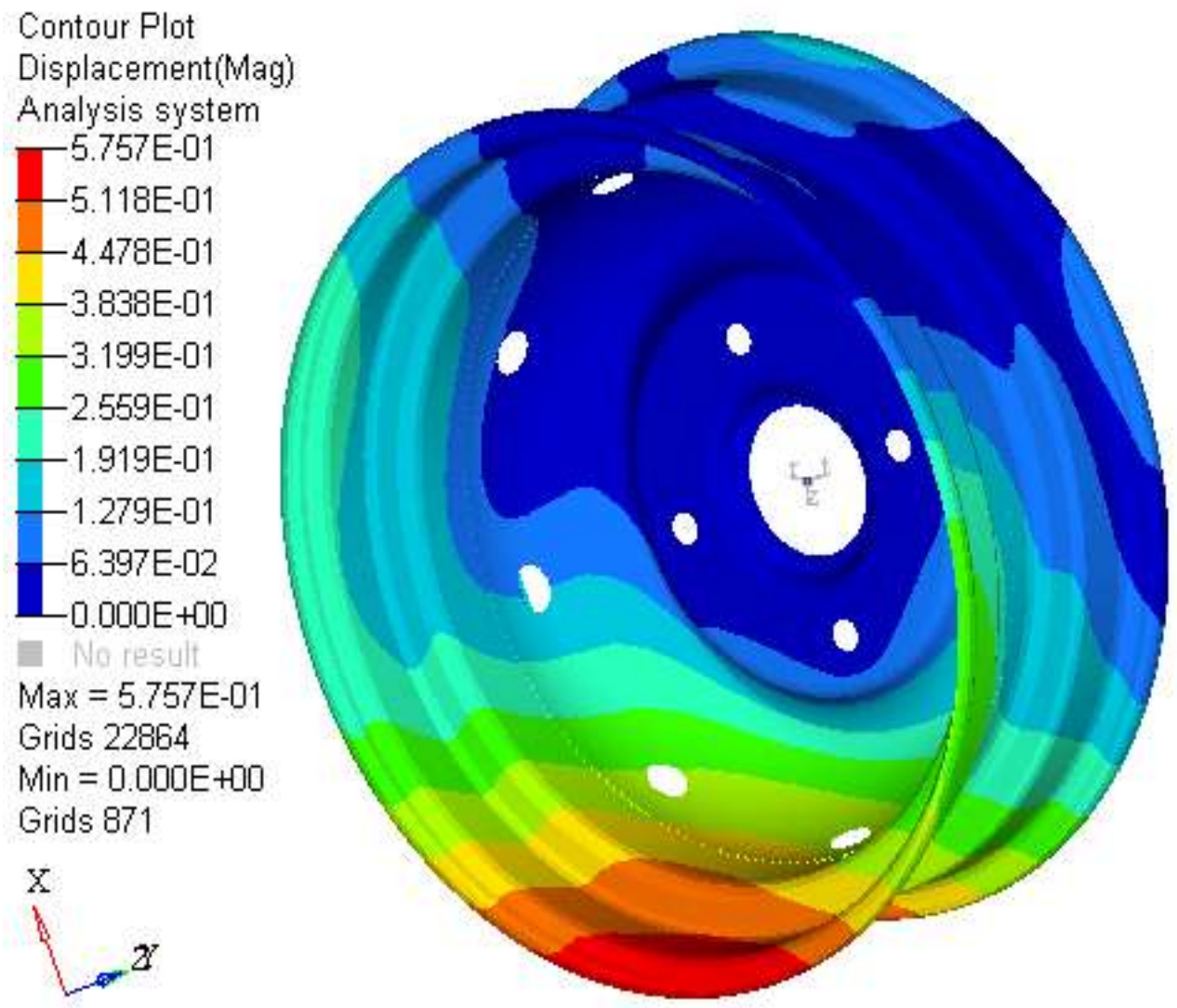

Fig. 3:- Displacement plot of existing rim 
Vonmises Stresses introduced in rim are as shown in fig. 4

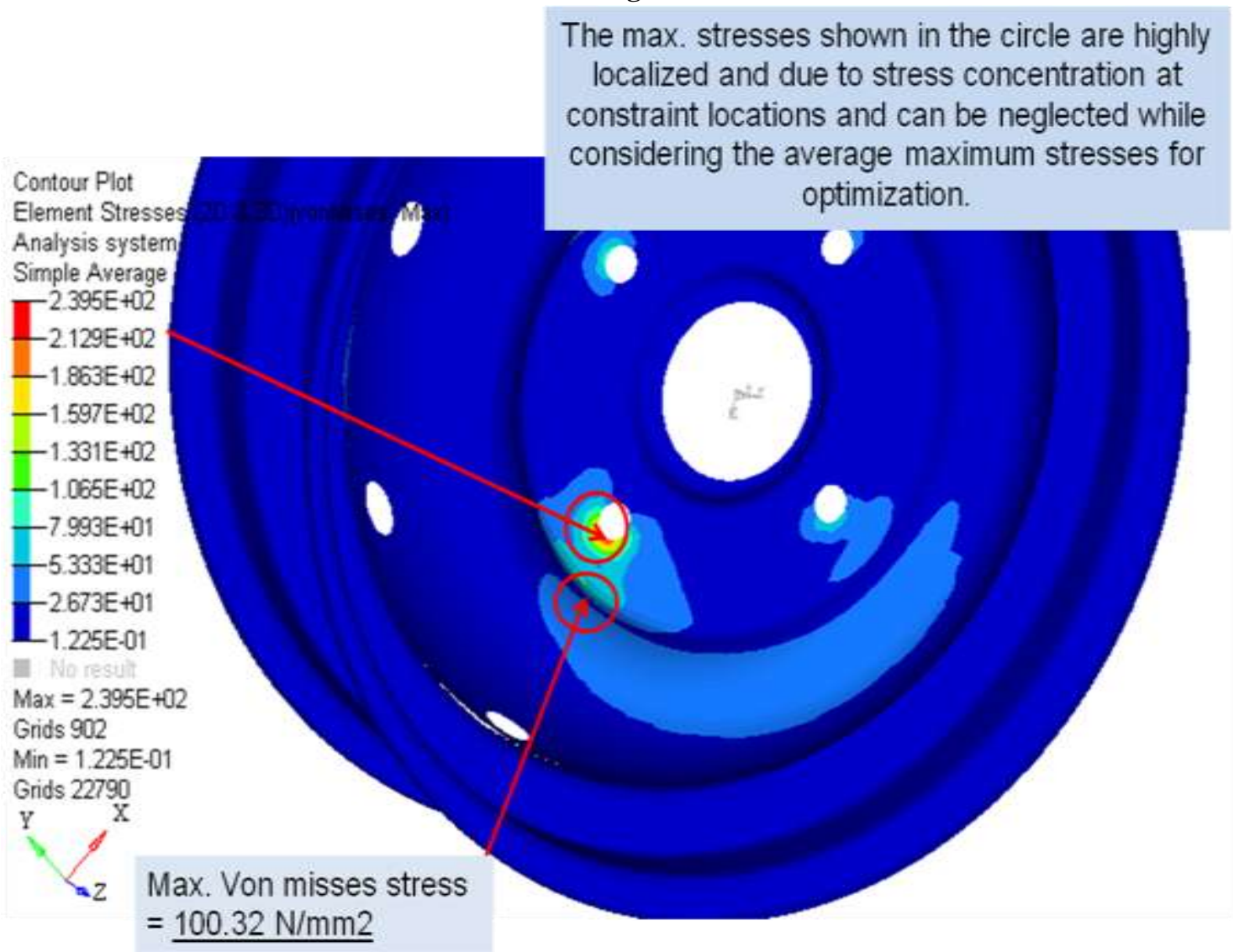

Fig. 4:- vonmises stresses consist in existing rim

From the analysis of Existing rim following results were observed.

Table 2: Results of existing car rim.

\begin{tabular}{|c|c|c|}
\hline Car rim & kimum displacement (mm) & Maximum stress $\left(\mathrm{N} / \mathrm{mm}^{2}\right)$ \\
\hline Existing & 0.5757 & 100.32 \\
\hline
\end{tabular}

As the values of displacement $\&$ stress were within the permissible range, we will repeat the procedure for next case by reducing the rim thickness. The results of no. of iterations were as shown in table 3 .

Table 3: Results of iteration

\begin{tabular}{|c|c|c|c|}
\hline $\begin{array}{c}\text { Outer thickness } \\
(\mathbf{m m})\end{array}$ & $\begin{array}{c}\text { Inner thickness } \\
(\mathbf{m m})\end{array}$ & $\begin{array}{c}\text { Displacement } \\
(\mathbf{m m})\end{array}$ & $\begin{array}{c}\text { Vonmises } \\
\text { stress(n/mm }\end{array}$ \\
\hline 2.75 & 2.75 & 1.3438 & 110.33 \\
\hline 2.5 & 2.5 & 1.8395 & 131.76 \\
\hline 2.25 & 2.25 & 2.2638 & 160.03 \\
\hline 2. & 2.25 & 2.3563 & 160.92 \\
\hline 2 & 2.5 & 2.172 & 133.2 \\
\hline
\end{tabular}

For optimum condition displacement of rim is as shown in Fig. 5 
Contour Plot Displacement (Mag Analysis systom

$-2.172 \mathrm{E}+00$

1. $.899 E+O C$

1. $44 \mathrm{EE}+\mathrm{OOC}$

1. $207 E+00$

9. 553 E- 01

7.240E-01

4.826E-01

$2,413 E-\square 1$

Q. 000 E +OC

Max $-2.172 E+00$

Gride 2286

Min - D OOOE +OO

Grids 871
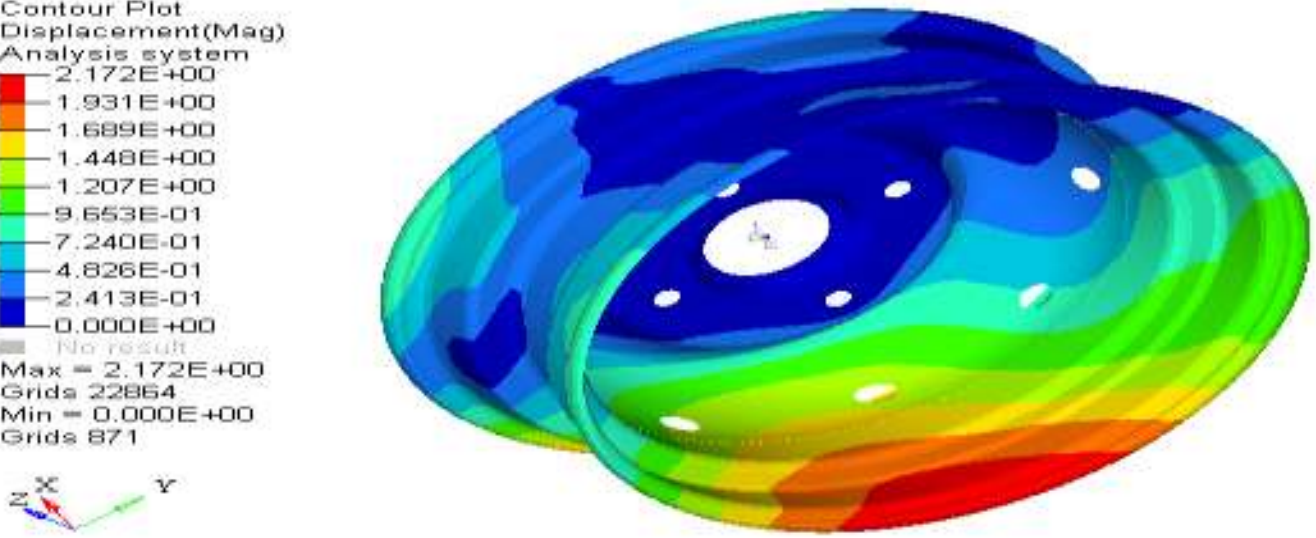

Fig. 5:- Displacement of rim in its optimum condition

von mises Stresses in rim at its optimum condition are as shown in Fig. 6

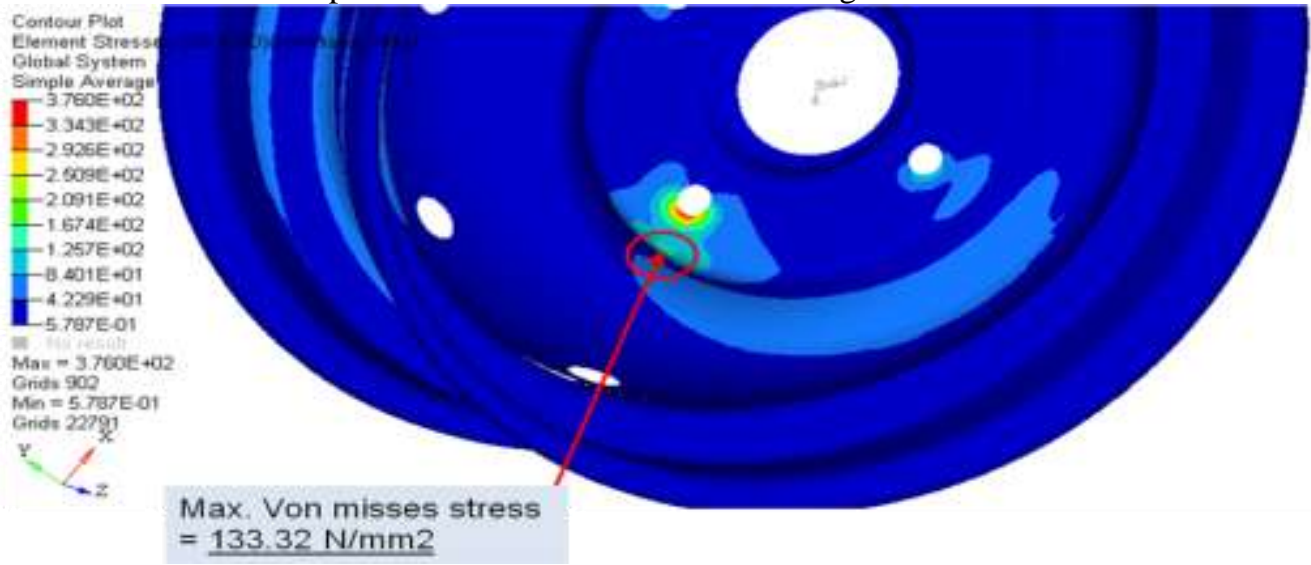

Fig. 6:- vonmises stresses in rim at its optimum condition

IV. Experimental Setup:-

For experimental stress measurement purpose strain gauge with strain indicator is used.To measure the stresses induced in rim by experimentally is very difficult task because it requires development of die for applying load. There for to validate the results in the FEA analysis obtained by Ansys software, consider a simple object which consist same geometry as like rim with same material property and boundary conditions. The simple testing component used for analysis is as shown in fig. 7.

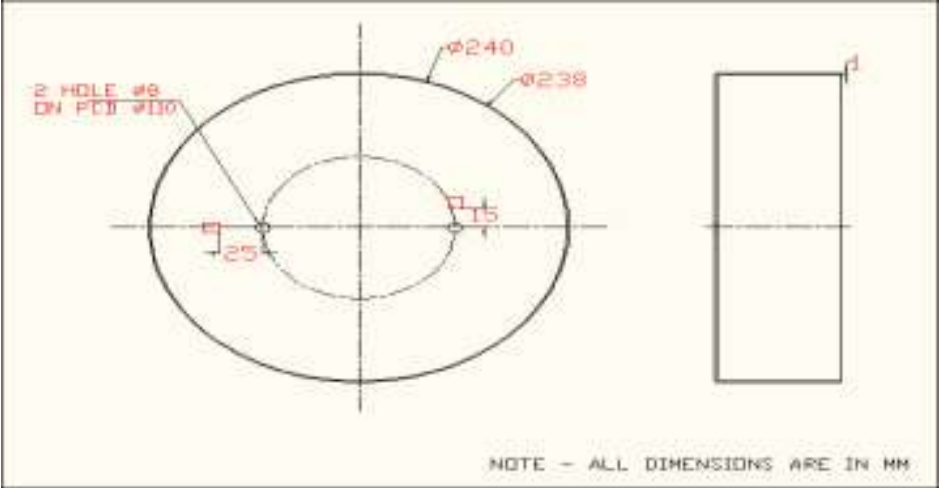

Fig. 7:- 2D view of testing component

Where,

Shows location of strain gauges for strain measurement.

The values of stresses in shown location are measured with strain gauge.the experimental setup as shown in Fig.8 


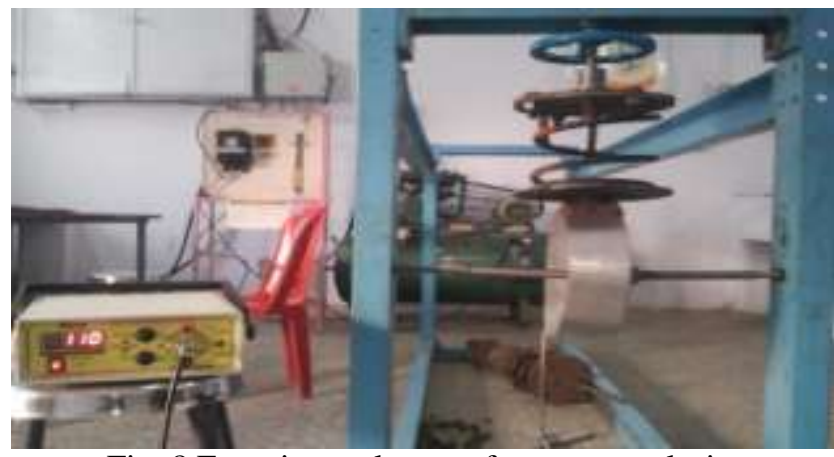

Fig. 8 Experimental set up for stress analysis.

The resultant stresses obtained by stress analysis are as shown in Table 4

Table 4. Experimental stress analysis in testing component.

\begin{tabular}{|l|l|l|l|}
\hline Sr. No. & Load & Stress value & Direction \\
\hline 1 & $246 \mathrm{~N}$ & 100 & Along Y axis (in vertical Direction) \\
\hline 2 & $246 \mathrm{~N}$ & 45 & Along X axis (in horizontal Direction) \\
\hline
\end{tabular}

Same component is tested for the given load in ansys software. The compared results of both are as shown in Table 5 .

Table 5:- comparison of experimental and analytical results.

\begin{tabular}{|c|c|c|c|c|}
\hline $\begin{array}{c}\text { Sr. } \\
\text { No. }\end{array}$ & Load & Stress $\left(\mathrm{N} / \mathrm{mm}^{2}\right)$ for Ansys & $\begin{array}{c}\text { Stress }\left(\mathrm{N} / \mathrm{mm}^{2}\right) \text { for } \\
\text { Experimental }\end{array}$ & $\%$ of difference \\
\hline 1 & $246 \mathrm{~N}$ & 110.5454 & 100 & 10.5454 \\
\hline 2 & $246 \mathrm{~N}$ & 46.96 & 45 & 4.356 \\
\hline
\end{tabular}

From above table it is shown that stress values in experimental analysis and analytical analysis are same.

\section{Conclusion:-}

This work presents weight optimization of car rim using finite element method for maximum stress of $135 \mathrm{~N} / \mathrm{mm}^{2}$. Using FEA software ANSYS directly 3-D descritised model of rim is build with shell 281 elements. The thickness of rim was reduced from $3 \mathrm{~mm}$ (both for outer and inner) to outer $2 \mathrm{~mm}$ and inner 2.5 $\mathrm{mm}$. This reduction was $13.28 \%$ for weight. Also, for validation of results similar kind of component is tested experimentally and analytically which shows experimental results are very close with analytical results. This shows that ansys is the valid software for stress analysis. Some deviation occurred in experimental as well as analytical result is due to improper mounting of strain gauge, climatic errors and loading unloading errors.

\section{Reference:-}

[1] H. Akbulut, On optimisation of car rim using finite element method, Finite element analysis and design, 39 (2003), page $433-443$

[2] A.Duster, D. scholz and E. Rank, pq-Adaptive solid finite elements for three dimensional plate and shell, computer methods in applied mechanics and engineering. 197 (2007) page no. 243-254

[3] Nikolos D. lagaros, Michalis fragiadakis and manolis papadrakasis, optimum design of shell structures with stiffening beam, AIAA Journal, vol. 42, No. 1, January 2004.

[4] MAO Jia, CHEN YuFeng and ZHANG WeiHua, An experimental optimization design method for orthogonal rib-stiffened thin walled cylindrical shells under axial loading, Applied mechanics and materials vols. 110-116, trans tech publication Switzerland.

[5] J. Awrejcewicza, V.A. Kryskob, Some problems of analysis and optimization of plates and shells, journal of sound and vibration 264 (2003) Page No. 343-376.

[6] Hiroshi OHMORI and Kenji YAMAMOTO, Shape optimization of shell and Spatial structure for specified Stress distribution, Memories of the school of engineering, Nagoya University, Vol.50, No.1 (1998)

[7] O. V. Zhmuru and Yu. M. Pochtman, Dynamical optimisation of ribbed cylindrical shells under the action of periodic nonharmonic loads, Journal of mathematical sciences, Vol. 70, No. 5. 